\title{
AVALIAÇ̃̃o MICROBIOLÓGICA DE BEBIDAS LÁCTEAS FERMENTADAS ADQUIRIDAS NO COMÉRCIO VAREJISTA DO SUL DE MINAS GERAIS*
}

\author{
Microbiological evaluation of fermented dairy beverages acquired in the retail marked of the \\ southern region of Minas Gerais State
}

\author{
Victor Maximiliano Reis Tebaldi ${ }^{1}$, Jaíne das Graças Oliveira Silva Resende ${ }^{2}$, Guilherme Cabral de Ávila Ramalho ${ }^{3}$, \\ Thales Leandro Coutinho de Oliveira ${ }^{3}$, Luiz Ronaldo de Abreu ${ }^{4}$, Roberta Hilsdorf Piccoli ${ }^{5}$
}

\begin{abstract}
RESUMO
O objetivo deste trabalho foi avaliar as características microbiológicas das bebidas lácteas fermentadas comercializadas no sul de Minas Gerais. Realizou-se a enumeração coliformes totais e termotolerantes, fungos filamentosos e leveduras e bactérias lácticas. Foram coletadas amostras de cinco marcas de bebidas lácteas comercializadas em Lavras, com quatro repetições, de diferentes lotes de fabricação, para serem submetidas às análises microbiológicas. As bebidas lácteas fermentadas apresentaram-se dentro dos padrões estipulados pela ANVISA quanto à presença de contaminação microbiana, pois os mesmos não foram detectados nas amostras analisadas. A contagem de bactérias láticas foi menor que $10^{6} \mathrm{UFC} / \mathrm{mL}$ em todas as análises, apresentando-se fora dos padrões estabelecidos pela legislação brasileira para as bebidas lácteas fermentadas.
\end{abstract}

Termos para indexação: Bebidas lácteas fermentadas, contaminação, bactérias láticas.

\begin{abstract}
The objective of this work was to evaluate the microbiological characteristics of fermented dairy beverages commercialized in southern Minas Gerais. The enumeration of total and heat-tolerant coliforms, filamentous fungi and lactic bacteria and yeasts was carried out. Samples were collected from different manufacturing lots of five brands of dairy beverages commercialized in Lavras-MG, with four repetitions and submitted to microbiological analyses. The fermented dairy beverages met the standards required by ANVISA for presence of microbial contamination, since no contamination was detected in the samples analyzed. Lactic bacteria count was lower than $10^{6} \mathrm{UFC} / \mathrm{mL}$ in all the analyses and did not meet out legal parameters established by the Brazilian legislation for fermented dairy beverages.
\end{abstract}

Index terms: Fermented dairy beverage, contamination, lactic bacteria.

(Recebido em 2 de junho de 2005 e aprovado em 5 de abril de 2006)

\section{INTRODUÇÃO}

Há grande preocupação dos órgãos de vigilância sanitária tanto da Agência Nacional de Vigilância Sanitaria (ANVISA), como pelo Instituto Mineiro de Agropecuária (IMA, 2003), pela inocuidade dos alimentos comercializados em todo o país e em Minas Gerais. A segurança alimentar tem sido alvo de muitas pesquisas científicas que acabam por mostrar que, grande parte dos alimentos comercializados se encontram fora dos padrões higiênicosanitários estabelecidos por lei, para garantir a saúde pública.

A origem de contaminação do leite e seus derivados por bactérias patogênicas varia com o tipo de produto e processamento, sendo a contaminação de origem endógena ou exógena, sendo esta via ambiente (BRISABOIS et al., 1997). A presença de vários patógenos são relatados em produtos lácteos, principalmente em queijos. Em Belo Horizonte, 168 amostras de queijo Minas foram avaliadas, quanto à quantificação de coliformes fecais, sendo que 110 queijos continham número de coliformes fecais superior ao permitido por lei (PEREIRA et al., 1999). Como evidenciado no trabalho de Pereira et al. (1999) os produtos lácteos têm grande incidência de inconformidades com a legislação vigente. Em 1999 um surto, ocorrido nos municípios de Manhuaçu e Passa-

\footnotetext{
*Trabalho desenvolvido no Laboratório de Microbiologia de Alimentos do Departamento de Ciência dos Alimentos da Universidade Federal de Lavras/UFLA. 'Doutorando em Ciência dos Alimentos - Departamento de Ciência dos Alimentos/DCA - Universidade Federal de Lavras/UFLA - Cx. P. 3037 37200-000 - Lavras, MG - victormaxibio@yahoo.com.br

${ }^{2}$ Mestre em Microbiologia Agrícola - Faculdade de Educação e Estudos Sociais - Universidade Presidente Antônio Carlos/UNIPAC - Avenida Leite de Castro, 101, Fábrica - 36301-182 - São João Del Rei, MG - jaineresende@bol.com.br

${ }^{3}$ Graduandos em Engenharia de Alimentos - Departamento de Ciência dos Alimentos/DCA - Universidade Federal de Lavras/UFLA - Cx. P. 3037 37200-000 - Lavras, MG - cabral84@yahoo.com.br; thalyns@bol.com.br

${ }^{4}$ Doutor, Professor Titular - Departamento de Ciência dos Alimentos/DCA - Universidade Federal de Lavras/UFLA - Cx. P. 3037 - $37200-000$ Lavras, MG - Irabreu@ufla.br

${ }^{5}$ Doutora, Professora Adjunto - Departamento de Ciência dos Alimentos/DCA - Universidade Federal de Lavras/UFLA - Cx. P. 3037 - $37200-000$ Lavras, MG - rhpiccoli@ufla.br
} 
Quatro de toxinose, causada por Staphylococcus aureus veiculado por queijo Minas frescal, foi relatado por Carmo et al. (2002). Segundo a ANVISA (BRASIL, 2001) leites fermentados não devem conter valores de coliformes termotolerantes, acima de $10 \mathrm{NMP} / \mathrm{mL}$. Embora não se tenha encontrado na literatura relatos de sobrevivência de coliformes em iogurte ou bebidas lácteas, outros microrganismos são relatados. Dentre eles, encontra-se a Escherichia coli O157: H7 e outras cepas de $E$. coli que também apresentam a capacidade de sobreviver em alimentos ácidos como o iogurte, por considerável período (LEE \& CHEN, 2005). Salmonella sp também é outro microrganismo que possui boa sobrevivência em iogurtes, mesmo com a acidificação provocada pela cultura starter (NASSIB et al., 2006). Além de bactérias, leveduras foram isoladas de várias amostras de iogurte. Foram avaliadas 128 amostras de iogurte e, nessas, foram encontradas leveduras dos gêneros Torulopsis, Kluyveromyces, Saccharomyces, Candida, Rhodotorula, Pichia, Debaromyces e Sporobolomyces (FLEIT, 1981). Segundo a resolução $\mathrm{n}^{\circ}$ 5, de 13 de novembro de 2000 do Ministério da Agricultura Pecuária e do Abastecimento, os leites fermentados devem apresentar, no mínimo, o número de $10^{6} \mathrm{UFC} / \mathrm{mL}$ de bactérias láticas totais, não sendo esse valor alcançado, o produto se encontra em nãoconformidade com seu Regulamento Técnico de Identidade e Qualidade (BRASIL, 2000).

O objetivo desse trabalho foi avaliar as condições higienico-sanitárias de leites fermentados comercializados no sul de Minas Gerais, certificando se estas apresentamse em conformidade com seu Padrão de Identidade e Qualidade.

\section{MATERIAL E MÉTODOS}

\section{Obtenção das amostras de bebidas lácteas}

As bebidas lácteas fermentadas foram coletadas no comércio da micro-região de Lavras, constituída pelos municípios de Carrancas, Ijací, Ingaí, Itumirim, Itutinga, Lavras, Luminárias, Nepomuceno e Ribeirão Vermelho. Das oito marcas disponíveis no Sul de Minas Gerais, cinco $(62,5 \%)$ (A, B, C, D e E) foram coletadas com quatro repetições, totalizando 20 amostras. Essas foram coletadas próximo ao dia de validade ( \pm 5 dias antes da data de validade) transportadas imediatamente para o Laboratório de Microbiologia de Alimentos do Departamento de Ciência dos Alimentos da Universidade Federal de Lavras.

\section{Preparo das amostras}

O conteúdo dos frascos de bebida láctea fermentada foi homogeneizado pela agitação, 20 vezes, do frasco ainda fechado. As aberturas dos frascos foram conduzidas, de forma asséptica, em câmara de fluxo laminar. Após abertura, alíquotas de $10 \mathrm{~mL}$ foram retiradas de cada embalagem com o auxílio de pipeta esterilizada e transferidas para um béquer com o objetivo da visualização de sua aparência. Assepticamente, alíquotas de $1 \mathrm{~mL}$ de amostras foram transferidas para frascos de diluição com $9 \mathrm{~mL}$ de água peptonada estéril a $0,1 \%(\mathrm{p} / \mathrm{v})$. A partir desta diluição foram feitas as diluições subseqüentes, necessárias à análise do produto.

\section{Análises microbiológicas}

Todas as análises microbiológicas foram realizadas de acordo com ICMSF (2000).

Determinação de coliformes totais

Alíquotas de $1 \mathrm{~mL}$ foram retiradas dos tubos contendo as amostras diluídas 10; 100 e 1000 vezes e transferidas para séries de 3 tubos contendo caldo Lauril Sulfato Triptose (LST) e homogeneizadas. Os tubos foram incubados à $35^{\circ} \mathrm{C} / 24-48$ horas.

Contagem de fungos filamentosos e leveduras

Para enumeração de fungos filamentosos e leveduras foi empregado ágar Batata Dextrose (BDA), acrescido de $0,2 \mathrm{~mL}$ de ácido tartárico $(10 \% \mathrm{p} / \mathrm{v})$, utilizandose o método de plaqueamento em superfície, semeando-se com alça de Drigalsky, seguido de incubação à $25^{\circ} \mathrm{C}$ por 5 dias.

Contagem de bactérias láticas viáveis

A contagem de bactérias lácticas foi realizada pelo método de plaqueamento em profundidade ou "pour plate", adicionando-se $1 \mathrm{~mL}$ de inóculo e derramando-se pequena quantidade de ágar MRS em placas de Petri. Após secagem do meio, uma sobrecamada foi adicionada, visando a criação de atmosfera de $15 \%$ de $\mathrm{CO}_{2}$, seguida de incubação a $30^{\circ} \mathrm{C}$ por 5 dias.

\section{RESULTADOS E DISCUSSÃO}

\section{Coliformes}

O teste presuntivo para coliformes revelou-se negativo para a presença dos mesmos, não se fazendo necessárias as etapas seguintes da colimetria (coliformes totais e termotolerantes). Devido ao baixo $\mathrm{pH}$ do produto 
sabe-se que esses microrganismos podem sofrer estresse e não serem detectados nas análises (FORSYTHE, 2002). Contudo, a ausência de coliformes no produto final, também pode ser indicativo de boas condições higiênico-sanitárias, durante o processo de elaboração das bebidas.

\section{Contagem de fungos filamentosos e leveduras}

Alguns fungos filamentosos são produtores de micotoxinas, as quais podem afetar a saúde humana e animal, não podendo ser encontrados em contagens elevadas. A presença de leveduras também fornece informações, tais como condições higiênico-sanitárias deficientes, multiplicação no produto em decorrência de falhas no processamento e/ou estocagem e matéria-prima com contaminação excessiva.

No entanto, não se detectou a presença de fungos filamentosos e leveduras nas bebidas analisadas, satisfazendo os padrões sugeridos por Arnott et al. (1974).

\section{Contagem de bactérias láticas}

Os resultados encontrados para contagem de bactérias láticas estão expressos na Tabela 1.

TABELA 1 - Contagem de bactérias lácticas em ágar MRS expressa em UFC/mL das diferentes marcas de bebidas lácteas fermentadas analisadas.

\begin{tabular}{cccccc}
\hline & \multicolumn{5}{c}{$\begin{array}{c}\text { Bactérias láticas } \\
\text { (UFC/mL) }\end{array}$} \\
\cline { 2 - 6 } Repetição & A & B & C & D & E \\
\hline 1 & $<10^{6}$ & $<10^{6}$ & $4,7 \times 10^{8}$ & $<10^{6}$ & $<10^{6}$ \\
2 & $<10^{6}$ & $<10^{6}$ & $2,6 \times 10^{8}$ & $<10^{6}$ & $<10^{6}$ \\
3 & $<10^{6}$ & $<10^{6}$ & $2,7 \times 10^{8}$ & $<10^{6}$ & $<10^{6}$ \\
4 & $<10^{6}$ & $<10^{6}$ & $3,2 \times 10^{8}$ & $<10^{6}$ & $<10^{6}$ \\
\hline
\end{tabular}

Das cinco marcas analisadas, apenas uma apresentou-se dentro dos padrões de contagens estabelecidos pelo Instituto Mineiro de Agropecuária (IMA, 2003), baseado na Instrução Normativa $n^{\circ} 36$ de 21/12/2000 (Ministério da Agricultura) e Resolução RDC no 12 de 02/01/ 2001 (ANVISA) que estabelece o valor mínimo de $10^{6} \mathrm{UFC} /$ $\mathrm{mL}$ de bactérias láticas em bebidas lácteas fermentadas.

A principal função das bactérias láticas nos alimentos é a acidificação destes produtos em $\mathrm{pH}$ próximo de quatro, o que impede o desenvolvimento de bactérias indesejáveis pela produção de ácidos orgânicos, majoritariamente ácido láctico (FORSYTHE, 2002). Isso permite que o tempo de conservação dos produtos fermentados seja muito maior que a dos produtos no qual a matéria-prima não foi fermentada. Outra função é desenvolver as propriedades organolépticas dos produtos fermentados.

\section{CONCLUSÕES}

Todas as amostras analisadas apresentaram boas condições higiênico-sanitárias, uma vez que não foram detectados coliformes, fungos filamentosos e leveduras. Porém, a contagem de bactérias láticas revelou-se insatisfatória em 4 amostras das 5 analisadas.

\section{REFERÊNCIAS BIBLIOGRÁFICAS}

ARNOTT, D. R.; DUITSCHAEVE, R. C. L.; BULLOCK, D. H. Microbiological evaluation of yogurt produced commercially in Ontario. Journal Milk, Food Technology, Ames, v. 37, n. 1, p. 11-13, Aug. 1974.

BRASIL. Ministério da Saúde. Resolução n. 12, de 12 de janeiro de 2001. Agência Nacional de Vigilância Sanitária (ANVISA). Diário Oficial da União, Brasília, n. 7-E, p. 4553, 10 jan. 2001. Seção 1.

BRASIL. Ministério da Agricultura, Pecuária e Abastecimento. Resolução n. 5, de 13 de novembro de 2000. Regulamento técnico de identidade e qualidade de leites fermentados. Disponível em: <http:// w w w. ng e t e c n o . c o m. b r / l e g i s 1 a çã o / leite_piq_leite_fermentado.htm>. Acesso em: 26 jul. 2006.

BRISABOIS, A.; LAFARGE, V.; BROIULLAUD, A.; BERYSER, M. L.; COLLETE, C.; GAREN-BASLEYI; THOREEL, M. F. Pathogenic microorganisms in milk and dairy products: the situation in France and Europe. Science Technology Office International Epizootics, [S.1.], v. 16, p. 452-471, 1997.

CARMO, L. S.; DIAS, R. S.; LINARDI, V. R.; SENA, M. J.; SANTOS, D. A.; FARIA, M. E.; PENA, E. C.; JETT, M.; HENEINE, G. Food poisoning due to enterotoxigenic srains os Staphylococcus presente in Minas cheese and raw milk in Brazil. Food Microbiology, [S.1.], v. 19, p. 9-14, 2002.

FLEIT, G. H. Occurrence na growth of yeast in yogurts Suriyarachchi VR. Applied Environmental Microbiology, [S.l.], v. 42, p. 574-579, 1981. 
FORSYTHE, S. J. Microbiologia da segurança alimentar. Porto Alegre: Artmed, 2002.

INSTITUTO MINEIRO DE AGROPECUÁRIA. Instrução de serviço DIPA n ${ }^{\circ}$ 001/03. Belo Horizonte, 2003.

INTERNATIONAL COMMISSION ON MICROBIOLOGICAL SPECIFICATION FOR FOODS. Microorganismos de los alimentos: su significado y metodos de emuneración. 2. ed. Zaragoza: Acribia, 2000 $367 \mathrm{p}$.

LEE, S. M.; CHEN, J. The influence of extracellular polysaccharide, comprised of calanic acid, on the fate Escherichia coli $\mathrm{O} 157: \mathrm{H7}$ during processing and storage of stirred yogurt. Food Science and Technology, [S.1.], v. 38, p. 785-790, 2005.

NASSIB, T. A.; EL-DIN, M. Z.; EL-SHAROUD, W. M. Effect of thermophilic lactic acid bacteria on the viability of Salmonella serovar Typhimurium PT8 during milk fermentation and preparation of buffalo's yogurt. International Journal of Dairy Technology, [S.1.], v. 59, p. 29-34, 2006.

PEREIRA, M. L.; GASTELOIS, M. C. A.; BASTOS, E. M. A. F.; CAIFFA, W. T.; FALEIRO, E. S. C. Enumeração de coliformes fecais e presença de Salmonella sp. em queijo Minas. Arquivo Brasileiro de Medicina Veterinária e Zootecnia, Belo Horizonte, v. 51, p. 427-431, 1999. 